\title{
Periventricular leukomalacia is common after neonatal cardiac surgery
}

Kristen K. Galli, MD, ${ }^{a}$ Robert A. Zimmerman, MD, ${ }^{b}$ Gail P. Jarvik, MD, PhD, ${ }^{f}$ Gil Wernovsky, MD, ${ }^{c}$ Marijn K. Kuypers, MD, ${ }^{c}$ Robert R. Clancy, MD, ${ }^{d}$ Lisa M. Montenegro, MD, ${ }^{a}$ William T. Mahle, MD, ${ }^{g}$ Mark F. Newman, MD, ${ }^{\mathrm{h}}$

Ann M. Saunders, PhD, ${ }^{i}$ Susan C. Nicolson, MD, ${ }^{a}$ Thomas L. Spray, MD, ${ }^{\mathrm{e}}$ and J. William Gaynor, MD

Because of a potential conflict of interest related to this manuscript on the part of our editors, Dr Richard Jonas served as guest editor (guest section editor), assigned reviewers, and made editorial decisions or recommendations leading to its acceptance for publication.

From the Divisions of Cardiothoracic Anesthesiology, ${ }^{a}$ Neuroradiology, ${ }^{\mathrm{b}}$ Pediatric Cardiology, ${ }^{\mathrm{c}}$ Neurology, ${ }^{\mathrm{d}}$ and Cardiothoracic Surgery, ${ }^{\mathrm{e}}$ The Cardiac Center at The Children's Hospital of Philadelphia, Philadelphia, Pa; Department of Medicine (Medical Genetics), ${ }^{f}$ University of Washington, Seattle, Wash; Division of Pediatric Cardiology, ${ }^{\mathrm{g}}$ Emory University School of Medicine, Atlanta, Ga; and the Departments of Anesthesiology and Neurology, ${ }^{\mathrm{h}}$ Duke University Medical Center, Durham, NC.

Supported by grants from the Fourjay Foundation and The American Heart Association (9950480).

Read at the Eighty-third Annual Meeting of The American Association for Thoracic Surgery, Boston, Mass, May 4-7, 2003.

Address for reprints: J. W. Gaynor, MD, Division of Cardiothoracic Surgery, The Children's Hospital of Philadelphia, 34th and Civic Center Boulevard, Suite 8527, Philadelphia, PA 19104 (E-mail: gaynor@email.chop.edu).

J Thorac Cardiovasc Surg 2004;127: 692-704

$0022-5223 / \$ 30.00$

Copyright ( $\odot 2004$ by The American Association for Thoracic Surgery

doi:10.1016/j.jtcvs.2003.09.053
Objectives: Periventricular leukomalacia is necrosis of the cerebral white matter adjacent to the lateral ventricles and results from injury to immature oligodendroglia. In infants without congenital heart disease, periventricular leukomalacia is associated with an increased incidence of developmental delay and attention deficit/ hyperactivity disorder. The incidence of periventricular leukomalacia and the risk factors for development of periventricular leukomalacia after infant cardiac surgery are not known.

Methods: Magnetic resonance imaging of the brain was performed 6 to 14 days after cardiac surgery utilizing cardiopulmonary bypass with or without deep hypothermic circulatory arrest in 105 neonates and infants $\leq 6$ months of age.

Results: Median age at surgery was 6 days (range 1-178), with 82 neonates (age $\leq$ 30 days). Periventricular leukomalacia was found in 44 of the neonates $(54 \%)$ compared with 1 of 23 infants (4\%). Forward logistic regression using age at surgery as a continuous variable identified a model containing longer total support time (cardiopulmonary bypass plus deep hypothermic circulatory arrest), lower systolic blood pressure at cardiac intensive care unit admission postoperatively, lower minimum diastolic blood pressure, and $\mathrm{PO}_{2}$ in the first 48 hours after surgery. When age at surgery was considered as a dichotomous variable (neonate versus infant), younger age at surgery replaced systolic blood pressure, $\mathrm{Po}_{2}$, and total support time in the model. Lower minimum diastolic blood pressure was a significant risk factor in both models.

Conclusions: Periventricular leukomalacia was found in $>50 \%$ of neonates after cardiac surgery but rarely in older infants. Hypoxemia and hypotension in the early postoperative period, particularly diastolic hypotension, may be important risk factors for periventricular leukomalacia.

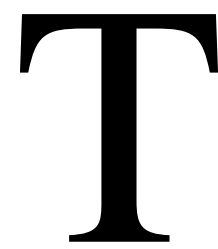

here has been a dramatic reduction in mortality following surgery for complex congenital heart defects in the past 2 decades. Unfortunately, there has also been increasing recognition of adverse neurodevelopmental sequelae in some survivors. ${ }^{1-5}$ Evaluation of children following neonatal repair of congenital heart disease (CHD) demonstrates a pattern of neurodevelopmental sequelae characterized by mild cognitive impairment, speech and language abnormalities, impaired visualspatial and visual-motor skills, attention deficit/hyperactivity disorder (ADHD), motor delays, as well as learning disabilities. ${ }^{3-5}$ Cerebral ischemia in the perioperative period has been proposed to be a primary mechanism of central nervous 
system (CNS) injury. ${ }^{6}$ Management strategies during surgery including type of support (deep hypothermic circulatory arrest [DHCA] or continuous cardiopulmonary bypass $[\mathrm{CPB}]$ ), hemodilution, degree of cooling, and blood gas management have been implicated as factors in postoperative neurodevelopmental dysfunction. ${ }^{1-6}$ However, there is increasing evidence that CNS injury may also occur during both the preoperative and postoperative periods. ${ }^{6}$ Neuroimaging and pathological studies suggest that cerebral white matter injury characterized by periventricular leukomalacia (PVL) is common in infants with CHD, especially after surgery. ${ }^{7-9}$ The current study was undertaken to evaluate the occurrence of PVL following cardiac surgery in neonates and infants, as well as to evaluate potential risk factors.

\section{Methods}

\section{Inclusion Criteria}

A subgroup of children enrolled in a prospective study evaluating polymorphisms of Apolipoprotein E (APOE) as a risk factor for neurodevelopmental dysfunction also underwent early postoperative (1-2 weeks) magnetic resonance imaging (MRI) of the brain. Patients $\leq 6$ months of age undergoing CPB, with or without DHCA, for repair of CHD were eligible. Exclusion criteria included (1) multiple congenital anomalies; (2) recognizable genetic or phenotypic syndrome other than chromosome 22q11 microdeletions; and (3) language other than English spoken in the home. The study was approved by the Institutional Review Board at The Children's Hospital of Philadelphia. Informed consent was obtained from the parent or guardian.

\section{Operative Management}

Surgery was performed by 4 cardiac surgeons with a dedicated team of cardiac anesthesiologists. Alpha-stat blood gas management was utilized. DHCA was utilized at the surgeon's discretion. Prior to DHCA, patients underwent core cooling with topical hypothermia of the head to a nasopharyngeal temperature of $18^{\circ} \mathrm{C}$. Modified ultrafiltration was performed in all patients.

\section{Data Collection}

Data collected included gestational age, head circumference, birth weight, and Apgar scores, which were obtained from birth records. Weight and age at surgery and type of surgery were recorded, along with $\mathrm{CPB}$ time, aortic crossclamp time, and duration of DHCA. Total support time was calculated as CPB time plus DHCA time. Postoperative hemodynamic data including heart rate (HR), systolic blood pressure (SBP), diastolic blood pressure (DBP), and right atrial pressure (RAP) were retrospectively recorded from the cardiac intensive care unit (CICU) flow sheet at 4-hour intervals for the first 48 hours postoperatively. Arterial blood gas data including $\mathrm{pH}, \mathrm{PO}_{2}$, and $\mathrm{PCO}_{2}$ were recorded at the same intervals.

\section{Postoperative MRI}

MRI of the brain was performed in the early postoperative period between 3 and 14 days after surgery. All patients were transported to and from the MRI scanner, cared for, and, if necessary, sedated
TABLE 1. Logistic regression of each predictor on PVL separately

\begin{tabular}{|c|c|c|c|}
\hline Predictors & B & Standard error & $P$ value \\
\hline \multicolumn{4}{|l|}{ Preoperative factors } \\
\hline Apgar1 & 0.170 & 0.148 & .251 \\
\hline Apgar5 & -0.343 & 0.317 & .280 \\
\hline $\begin{array}{l}\text { Birth head circumference } \\
(\%)\end{array}$ & -0.001 & 0.006 & .895 \\
\hline Birth weight (\%) & -0.006 & 0.007 & .389 \\
\hline APOE 22 or 23 & 0.396 & 0.740 & .593 \\
\hline APOE 34 or 44 & -0.374 & 0.478 & .435 \\
\hline Gestational age & -0.144 & 0.097 & .139 \\
\hline Gestational age $(<37, \geq 37)$ & -1.107 & 0.648 & $.087^{*}$ \\
\hline Diagnostic code & $\mathrm{n} / \mathrm{a}$ & $\mathrm{n} / \mathrm{a}$ & $.019 *$ \\
\hline Sex & 0.298 & 0.402 & .458 \\
\hline \multicolumn{4}{|l|}{ Operative factors } \\
\hline Age at surgery & -0.031 & 0.011 & $.007^{*}$ \\
\hline Age at surgery $(<31, \geq 31)$ & -3.234 & 1.045 & $.002^{*}$ \\
\hline Weight & -0.707 & 0.236 & $.003^{*}$ \\
\hline Operative class & $\mathrm{n} / \mathrm{a}$ & $\mathrm{n} / \mathrm{a}$ & $.003^{*}$ \\
\hline CPB & 0.004 & 0.004 & .383 \\
\hline DHCA (Y/N) & 1.128 & 0.432 & $.009^{*}$ \\
\hline DHCA & 0.024 & 0.009 & $.005^{*}$ \\
\hline Hematocrit & 0.011 & 0.057 & .840 \\
\hline Support & 0.014 & 0.005 & $.009^{*}$ \\
\hline Surgeon & $\mathrm{n} / \mathrm{a}$ & $\mathrm{n} / \mathrm{a}$ & .427 \\
\hline \multicolumn{4}{|l|}{ Postoperative factors } \\
\hline $\mathrm{DBP}_{\mathrm{adm}}$ & -0.091 & 0.023 & $.000^{*}$ \\
\hline $\mathrm{DBP}_{\max }^{\mathrm{adm}}$ & -0.079 & 0.021 & $.000^{*}$ \\
\hline $\mathrm{DBP}_{\min }$ & -0.189 & 0.045 & $.000^{*}$ \\
\hline $\mathrm{HR}_{\mathrm{adm}}$ & -0.007 & 0.008 & .432 \\
\hline $\mathrm{HR}_{\max }$ & -0.004 & 0.007 & .599 \\
\hline $\mathrm{HR}_{\min }^{\max }$ & 0.028 & 0.013 & $.027^{*}$ \\
\hline $\mathrm{PCO}_{2 \mathrm{adm}}$ & -0.016 & 0.027 & .557 \\
\hline $\mathrm{PCO}_{2 \max }$ & 0.028 & 0.028 & .325 \\
\hline $\mathrm{PCO}_{2 \min }$ & 0.028 & 0.046 & .540 \\
\hline $\mathrm{pH}_{\mathrm{adm}}$ & 0.307 & 2.290 & .893 \\
\hline $\mathrm{pH}_{\max }$ & 2.133 & 3.415 & .532 \\
\hline $\mathrm{pH}_{\min }$ & -3.756 & 3.010 & .212 \\
\hline $\mathrm{Po}_{2 \text { adm }}$ & -0.002 & 0.001 & $.046^{*}$ \\
\hline $\mathrm{Po}_{2 \max }$ & -0.003 & 0.001 & $.023^{*}$ \\
\hline $\mathrm{Po}_{2 \min }$ & -0.048 & 0.016 & $.002^{*}$ \\
\hline $\mathrm{RAP}_{\mathrm{adm}}$ & -0.026 & 0.051 & .611 \\
\hline $\mathrm{RAP}_{\max }^{\mathrm{adm}}$ & -0.039 & 0.044 & .379 \\
\hline $\mathrm{RAP}_{\min }$ & -0.015 & 0.107 & .890 \\
\hline $\mathrm{SBP}_{\mathrm{adm}}^{\mathrm{min}}$ & -0.061 & 0.017 & $.000^{*}$ \\
\hline $\mathrm{SBP}_{\max }$ & -0.046 & 0.016 & $.003^{*}$ \\
\hline $\mathrm{SBP}_{\min }$ & -0.082 & 0.024 & $.001^{*}$ \\
\hline
\end{tabular}

$P V L$, Periventricular leukomalacia; $A P O E$, apolipoprotein $\mathrm{E} ; C P B$, cardiopulmonary bypass; $D H C A$, deep hypothermic circulatory arrest; $D B P$, diastolic blood pressure; $H R$, heart rate; $R A P$, right atrial pressure; $S B P$, systolic blood pressure; $n / a$, not applicable; adm, admission; $\max$, maximum; min, minimum; $B$, regression coefficient.

${ }^{*} P<.10$.

and/or anesthetized by cardiac anesthesiologists for the MRI examination. No patient was intubated exclusively for MRI and all patients recovered in the CICU.

MRI was performed with a 1.5 Tesla Magnetom magnet (Siemens, Munich, Germany). T1- and T2-weighted images were 
TABLE 2. Correlation matrix of quantitative PVL predictors

\begin{tabular}{|c|c|c|c|c|c|c|c|c|}
\hline Correlations & Class & $\begin{array}{c}\text { Gestational } \\
\text { age }\end{array}$ & $\begin{array}{l}\text { Age at } \\
\text { surgery }\end{array}$ & $\begin{array}{c}\text { Age at } \\
\text { surgery } 2\end{array}$ & $\begin{array}{c}\text { Weight at } \\
\text { surgery }\end{array}$ & $\begin{array}{l}\text { DHCA } \\
\text { (Y/N) }\end{array}$ & DHCA & $\begin{array}{c}\text { Support } \\
\text { time }\end{array}$ \\
\hline \multicolumn{9}{|l|}{ Class } \\
\hline Pearson Correlation & 1.000 & .052 & -.335 & -.410 & -.176 & .605 & .647 & -.033 \\
\hline$P($ 2-tailed $)$ & & .599 & $<.001^{*}$ & $<.001^{*}$ & .073 & $<.001^{*}$ & $<.001^{*}$ & .737 \\
\hline $\mathrm{n}$ & 105 & 105 & 105 & 105 & 105 & 105 & 105 & 105 \\
\hline \multicolumn{9}{|l|}{ Gestational age } \\
\hline Pearson Correlation & .052 & 1.000 & -.056 & -.027 & .304 & -.103 & -.054 & .153 \\
\hline$P$ (2-tailed) & .599 & & .570 & .785 & $.002^{*}$ & .294 & .585 & .119 \\
\hline $\mathrm{n}$ & 105 & 105 & 105 & 105 & 105 & 105 & 105 & 105 \\
\hline \multicolumn{9}{|l|}{ Age at surgery } \\
\hline Pearson Correlation & -.335 & -.056 & 1.000 & .861 & .763 & -.413 & -.382 & -.243 \\
\hline$P$ (2-tailed) & $<.001^{*}$ & .570 & & $<.001^{*}$ & $<.001^{*}$ & $<.001^{*}$ & $<.001^{*}$ & $.013^{*}$ \\
\hline $\mathrm{n}$ & 105 & 105 & 105 & 105 & 105 & 105 & 105 & 105 \\
\hline \multicolumn{9}{|l|}{ Age at surgery 2} \\
\hline Pearson Correlation & -.410 & -.027 & .861 & 1.000 & .630 & -.378 & -.398 & -.332 \\
\hline$P($ 2-tailed $)$ & $<.001^{*}$ & .785 & $<.001^{*}$ & & $<.001^{*}$ & $<.001^{*}$ & $<.001^{*}$ & $.001^{*}$ \\
\hline $\mathrm{n}$ & 105 & 105 & 105 & 105 & 105 & 105 & 105 & 105 \\
\hline \multicolumn{9}{|l|}{ Weight at surgery } \\
\hline Pearson Correlation & -.176 & .304 & .763 & .630 & 1.000 & -.458 & -.321 & -.113 \\
\hline$P$ (2-tailed) & .073 & $.002^{*}$ & $<.001^{*}$ & $<.001^{*}$ & & $<.001^{*}$ & $.001 *$ & .252 \\
\hline $\mathrm{n}$ & 105 & 105 & 105 & 105 & 105 & 105 & 105 & 105 \\
\hline \multicolumn{9}{|l|}{ DHCA (Y/N) } \\
\hline Pearson Correlation & .605 & -.103 & -.413 & -.378 & -.458 & 1.000 & .777 & .049 \\
\hline$P(2$-tailed $)$ & $<.001^{*}$ & .294 & $<.001^{*}$ & $<.001^{*}$ & $<.001^{*}$ & & $<.001^{*}$ & .621 \\
\hline $\mathrm{n}$ & 105 & 105 & 105 & 105 & 105 & 105 & 105 & 105 \\
\hline \multicolumn{9}{|l|}{ DHCA } \\
\hline Pearson Correlation & .647 & -.054 & -.382 & -.398 & -.321 & .777 & 1.000 & .142 \\
\hline$P$ (2-tailed) & $<.001^{*}$ & .585 & $<.001^{*}$ & $<.001^{*}$ & $.001^{*}$ & $<.001^{*}$ & & .149 \\
\hline $\mathrm{n}$ & 105 & 105 & 105 & 105 & 105 & 105 & 105 & 105 \\
\hline \multicolumn{9}{|l|}{ Support } \\
\hline Pearson Correlation & -.033 & .153 & -.243 & -.332 & -.113 & .049 & .142 & 1.000 \\
\hline$P($ 2-tailed) & .737 & .119 & $.013^{*}$ & $.001^{*}$ & .252 & .621 & .149 & \\
\hline $\mathrm{n}$ & 105 & 105 & 105 & 105 & 105 & 105 & 105 & 105 \\
\hline \multicolumn{9}{|l|}{$\mathrm{DBP}_{\mathrm{adm}}$} \\
\hline Pearson Correlation & -.516 & .173 & .391 & .437 & .310 & -.329 & -.404 & -.036 \\
\hline$P$ (2-tailed) & $<.001^{*}$ & .077 & $<.001^{*}$ & $<.001^{*}$ & $.001^{*}$ & $.001^{*}$ & $<.001^{*}$ & .715 \\
\hline $\mathrm{n}$ & 105 & 105 & 105 & 105 & 105 & 105 & 105 & 105 \\
\hline \multicolumn{9}{|l|}{$\mathrm{DBP}_{\max }$} \\
\hline Pearson Correlation & -.595 & .116 & .613 & .598 & .549 & -.497 & -.508 & -.146 \\
\hline$P$ (2-tailed) & $<.001^{*}$ & .238 & $<.001^{*}$ & $<.001^{*}$ & $<.001^{*}$ & $<.001^{*}$ & $<.001^{*}$ & .136 \\
\hline $\mathrm{n}$ & 105 & 105 & 105 & 105 & 105 & 105 & 105 & 105 \\
\hline \multicolumn{9}{|l|}{$\mathrm{DBP}_{\text {min }}$} \\
\hline Pearson Correlation & -.453 & .216 & .469 & .489 & .545 & -.388 & -.359 & -.095 \\
\hline$P($ 2-tailed $)$ & $<.001^{*}$ & $.027^{*}$ & $<.001^{*}$ & $<.001^{*}$ & $<.001^{*}$ & $<.001^{*}$ & $<.001^{*}$ & .334 \\
\hline $\mathrm{n}$ & 105 & 105 & 105 & 105 & 105 & 105 & 105 & 105 \\
\hline \multicolumn{9}{|l|}{$\mathrm{HR}_{\min }$} \\
\hline Pearson Correlation & .398 & .009 & -.327 & -.318 & -.240 & .377 & .323 & .118 \\
\hline$P($ 2-tailed) & $<.001^{*}$ & .924 & $.001^{*}$ & $.001^{*}$ & $.014^{*}$ & $<.001^{*}$ & $.001 *$ & .231 \\
\hline $\mathrm{n}$ & 105 & 105 & 105 & 105 & 105 & 105 & 105 & 105 \\
\hline \multicolumn{9}{|l|}{$\mathrm{Po}_{2 \mathrm{adm}}$} \\
\hline Pearson Correlation & -.617 & .122 & .185 & .290 & .091 & -.268 & -.320 & .109 \\
\hline$P($ 2-tailed $)$ & $<.001^{*}$ & .216 & .059 & $.003^{*}$ & .356 & $.006^{*}$ & $.001^{*}$ & .267 \\
\hline $\mathrm{n}$ & 105 & 105 & 105 & 105 & 105 & 105 & 105 & 105 \\
\hline \multicolumn{9}{|l|}{$\mathrm{Po}_{2 \max }$} \\
\hline Pearson Correlation & -.655 & .078 & .181 & .273 & .064 & -.255 & -.309 & .120 \\
\hline$P($ 2-tailed $)$ & $<.001^{*}$ & .430 & .065 & $.005^{*}$ & .517 & $.009^{*}$ & $.001^{*}$ & .224 \\
\hline$n$ & 105 & 105 & 105 & 105 & 105 & 105 & 105 & 105 \\
\hline $\mathrm{Po}_{2 \min }$ & & & & & & & & \\
\hline Pearson Correlation & -.628 & .007 & .332 & .380 & .165 & -.228 & -.423 & .104 \\
\hline$P(2$-tailed $)$ & $<.001^{*}$ & .944 & $.001^{*}$ & $<.001^{*}$ & .093 & $.019 *$ & $<.001^{*}$ & .291 \\
\hline $\mathrm{n}$ & 105 & 105 & 105 & 105 & 105 & 105 & 105 & 105 \\
\hline
\end{tabular}




\begin{tabular}{|c|c|c|c|c|c|c|c|c|c|}
\hline $\mathrm{DBP}_{\text {adm }}$ & $\mathrm{DBP}_{\max }$ & $\mathrm{DBP}_{\min }$ & $\mathrm{HR}_{\min }$ & $\mathbf{P o}_{\text {2adm }}$ & $\mathrm{Po}_{2 \max }$ & $\mathrm{Po}_{\text {2min }}$ & $\mathrm{SBP}_{\text {adm }}$ & $\mathrm{SBP}_{\max }$ & $\mathrm{SBP}_{\text {min }}$ \\
\hline-.516 & -.595 & -.453 & .398 & -.617 & -.655 & -.628 & -.234 & -.144 & .028 \\
\hline$<.001^{*}$ & $<.001^{*}$ & $<.001^{*}$ & $<.001^{*}$ & $<.001^{*}$ & $<.001^{*}$ & $<.001^{*}$ & $.017^{*}$ & .143 & .776 \\
\hline 105 & 105 & 105 & 105 & 105 & 105 & 105 & 105 & 105 & 105 \\
\hline .173 & .116 & .216 & .009 & .122 & .078 & .007 & .196 & .017 & .047 \\
\hline .077 & .238 & .027 & .924 & .216 & .430 & .944 & $.045^{*}$ & .862 & .636 \\
\hline 105 & 105 & 105 & 105 & 105 & 105 & 105 & 105 & 105 & 105 \\
\hline .391 & .613 & .469 & -.327 & .185 & .181 & .332 & .385 & .514 & .588 \\
\hline$<.001^{*}$ & $<.001^{*}$ & $<.001^{*}$ & $.001^{*}$ & .059 & .065 & $.001^{*}$ & $<.001^{*}$ & $<.001^{*}$ & $<.001^{*}$ \\
\hline 105 & 105 & 105 & 105 & 105 & 105 & 105 & 105 & 105 & 105 \\
\hline .437 & .598 & .489 & -.318 & .290 & .273 & .380 & .447 & .482 & .524 \\
\hline$<.001^{*}$ & $<.001^{*}$ & $<.001^{*}$ & $.001^{*}$ & $.003^{*}$ & $.005^{*}$ & $<.001^{*}$ & $<.001^{*}$ & $<.001^{*}$ & $<.001^{*}$ \\
\hline 105 & 105 & 105 & 105 & 105 & 105 & 105 & 105 & 105 & 105 \\
\hline .310 & .549 & .545 & -.240 & .091 & .064 & .165 & .266 & .377 & .564 \\
\hline $.001^{*}$ & $<.001^{*}$ & $<.001^{*}$ & $.014^{*}$ & .356 & .517 & .093 & $.006^{*}$ & $<.001^{*}$ & $<.001^{*}$ \\
\hline 105 & 105 & 105 & 105 & 105 & 105 & 105 & 105 & 105 & 105 \\
\hline-.329 & -.497 & -.388 & 377 & -.268 & -.255 & -.228 & -.191 & -.166 & -.253 \\
\hline $.001^{*}$ & $<.001^{*}$ & $<.001^{*}$ & $<.001^{*}$ & $.006^{*}$ & $.009 *$ & $.019 *$ & .051 & .091 & $.009 *$ \\
\hline 105 & 105 & 105 & 105 & 105 & 105 & 105 & 105 & 105 & 105 \\
\hline-.404 & -.508 & -.359 & .323 & -.320 & -.309 & -.423 & -.201 & -.181 & -.179 \\
\hline$<.001^{*}$ & $<.001^{*}$ & $<.001^{*}$ & $.001^{*}$ & $.001^{*}$ & $.001^{*}$ & $<.001^{*}$ & $.040^{*}$ & .065 & .067 \\
\hline 105 & 105 & 105 & 105 & 105 & 105 & 105 & 105 & 105 & 105 \\
\hline-.036 & -.146 & -.095 & .118 & .109 & .120 & .104 & -.108 & -.288 & -.365 \\
\hline .715 & .136 & .334 & .231 & .267 & .224 & .291 & .271 & .003 & $<.001^{*}$ \\
\hline 105 & 105 & 105 & 105 & 105 & 105 & 105 & 105 & 105 & 105 \\
\hline 1.000 & .719 & .636 & -.204 & .407 & .404 & .370 & .673 & .372 & .167 \\
\hline & $<.001^{*}$ & $<.001^{*}$ & .037 & $<.001^{*}$ & $<.001^{*}$ & $<.001^{*}$ & $<.001^{*}$ & $<.001^{*}$ & .088 \\
\hline 105 & 105 & 105 & 105 & 105 & 105 & 105 & 105 & 105 & 105 \\
\hline .719 & 1.000 & .673 & -.346 & .399 & .409 & .347 & .443 & .546 & .349 \\
\hline$<.001^{*}$ & & $<.001^{*}$ & $<.001^{*}$ & $<.001^{*}$ & $<.001^{*}$ & $<.001^{*}$ & $<.001^{*}$ & $<.001^{*}$ & $<.001^{*}$ \\
\hline 105 & 105 & 105 & 105 & 105 & 105 & 105 & 105 & 105 & 105 \\
\hline .636 & .673 & 1.000 & -.209 & .317 & .300 & .353 & .361 & .314 & .429 \\
\hline$<.001^{*}$ & $<.001^{*}$ & & $.032^{*}$ & $.001^{*}$ & $.002^{*}$ & $<.001^{*}$ & $<.001^{*}$ & $.001^{*}$ & $<.001^{*}$ \\
\hline 105 & 105 & 105 & 105 & 105 & 105 & 105 & 105 & 105 & 105 \\
\hline-.204 & -.346 & -.209 & 1.000 & -.182 & -.218 & -.122 & -.186 & -.190 & -.165 \\
\hline $.037^{*}$ & $<.001^{*}$ & $.032^{*}$ & & .063 & $.025^{*}$ & .216 & .058 & .052 & .093 \\
\hline 105 & 105 & 105 & 105 & 105 & 105 & 105 & 105 & 105 & 105 \\
\hline .407 & .399 & .317 & -.182 & 1.000 & .973 & .617 & .218 & .099 & -.087 \\
\hline$<.001^{*}$ & $<.001^{*}$ & $.001^{*}$ & .063 & & $<.001^{*}$ & $<.001^{*}$ & $.025^{*}$ & .313 & .378 \\
\hline 105 & 105 & 105 & 105 & 105 & 105 & 105 & 105 & 105 & 105 \\
\hline .404 & .409 & .300 & -.218 & .973 & 1.000 & .600 & .218 & .099 & -.099 \\
\hline$<.001^{*}$ & $<.001^{*}$ & $.002^{*}$ & $.025^{*}$ & $<.001^{*}$ & & $<.001^{*}$ & $.026^{*}$ & .315 & .315 \\
\hline 105 & 105 & 105 & 105 & 105 & 105 & 105 & 105 & 105 & 105 \\
\hline .370 & .347 & .353 & -.122 & .617 & .600 & 1.000 & .214 & .072 & -.076 \\
\hline$<.001^{*}$ & $<.001^{*}$ & $<.001^{*}$ & .216 & $<.001^{*}$ & $<.001^{*}$ & & .028 & .465 & .442 \\
\hline 105 & 105 & 105 & 105 & 105 & 105 & 105 & 105 & 105 & 105 \\
\hline
\end{tabular}


TABLE 2. Correlation matrix of quantitative PVL predictors

\begin{tabular}{|c|c|c|c|c|c|c|c|c|}
\hline Correlations & Class & $\begin{array}{c}\text { Gestational } \\
\text { age }\end{array}$ & $\begin{array}{l}\text { Age at } \\
\text { surgery }\end{array}$ & $\begin{array}{c}\text { Age at } \\
\text { surgery } 2\end{array}$ & $\begin{array}{c}\text { Weight at } \\
\text { surgery }\end{array}$ & $\begin{array}{l}\text { DHCA } \\
\text { (Y/N) }\end{array}$ & DHCA & $\begin{array}{c}\text { Support } \\
\text { time }\end{array}$ \\
\hline \multicolumn{9}{|l|}{$\mathrm{SBP}_{\mathrm{adm}}$} \\
\hline Pearson Correlation & -.234 & .196 & .385 & .447 & .266 & -.191 & -.201 & -.108 \\
\hline$P$ (2-tailed) & $.017^{*}$ & .045 & $<.001^{*}$ & $<.001^{*}$ & $.006^{*}$ & .051 & $.040^{*}$ & .271 \\
\hline $\mathrm{n}$ & 105 & 105 & 105 & 105 & 105 & 105 & 105 & 105 \\
\hline \multicolumn{9}{|l|}{$\mathrm{SBP}_{\max }$} \\
\hline Pearson Correlation & -.144 & .017 & .514 & .482 & .377 & -.166 & -.181 & -.288 \\
\hline$P$ (2-tailed) & .143 & .862 & $<.001^{*}$ & $<.001^{*}$ & $<.001^{*}$ & .091 & .065 & $.003^{*}$ \\
\hline $\mathrm{n}$ & 105 & 105 & 105 & 105 & 105 & 105 & 105 & 105 \\
\hline \multicolumn{9}{|l|}{$\mathrm{SBP}_{\min }$} \\
\hline Pearson Correlation & .028 & .047 & .588 & .524 & .564 & -.253 & -.179 & -.365 \\
\hline$P(2$-tailed $)$ & .776 & .636 & $<.001^{*}$ & $<.001^{*}$ & $<.001^{*}$ & $.009^{*}$ & .067 & $<.001^{*}$ \\
\hline $\mathrm{n}$ & 105 & 105 & 105 & 105 & 105 & 105 & 105 & 105 \\
\hline
\end{tabular}

performed in the axial plane, with $\mathrm{T} 1$ imaging also acquired in the sagittal and coronal planes. A gradient echo T2 axial scan was done for the susceptibility effects of blood products. All MRIs were reviewed and interpreted by a single neuroradiologist (R.A.Z.), using a scoring system for localizing and grading cerebral injury developed for this project. Most PVL is seen in this population as areas of increased signal intensity on T1-weighted images in the periventricular white matter. Small punctate areas (1 or more) of increased $\mathrm{T} 1$ signal (less than $3 \mathrm{~mm}$ ) were classified as mild PVL. These usually occur in the frontal and parietal regions and may be bilateral. When there were multiple small areas of increased T1 signal, between $3 \mathrm{~mm}$ and $1 \mathrm{~cm}$ in size, the PVL was classified as moderate. These may be bilateral in the frontal, parietal, and temporal regions but are not confluent. Larger confluent areas with plaques greater than $1 \mathrm{~cm}$, often bilateral, in the frontal, parietal, and sometimes temporal regions were classified as severe PVL.

\section{APOE Genotype Determination}

Whole blood was obtained prior to surgery and stored at $4{ }^{\circ} \mathrm{C}$. Genomic DNA was prepared and used to determine APOE genotypes utilizing a previously published method. ${ }^{10}$

\section{Data Analysis}

Patients were coded according to a previously described classification incorporating cardiac anatomy and perioperative physiology, which has been shown to be predictive of perioperative mortality. ${ }^{11}$ Class I is 2 ventricles with no aortic arch obstruction; class II is 2 ventricles with aortic arch obstruction; class III is single ventricle with no arch obstruction; and class IV is single ventricle with arch obstruction. Patients with tetralogy of Fallot (TOF) and transposition of the great arteries (TGA) are class I, while patients with hypoplastic left heart syndrome (HLHS) or variants are class IV. Patients were also grouped according to specific cardiac diagnoses: patients with HLHS; patients with conotruncal defects (TOF, TGA, truncus arteriosus, etc); and all other defects.

\section{Statistical Methods}

Data are presented as median and range, where appropriate. All predictors of PVL considered are listed in Table 1. Monitoring data $\left(\mathrm{Po}_{2}, \mathrm{PCO}_{2}, \mathrm{pH}, \mathrm{SBP}, \mathrm{DBP}, \mathrm{RAP}, \mathrm{HR}\right)$ had repeated measures from time zero (CICU admission) to 48 hours taken at 4-hour intervals. For each of these monitoring variables, the minimum and maximum values during the study period were identified and only time zero, minimum, and maximum values were considered. For SBP, for example, the variables $\mathrm{SBP}_{\mathrm{adm}}, \mathrm{SBP}_{\text {min }}$, and $\mathrm{SBP}_{\max }$ were considered. Three quantitative predictors were also dichotomized: gestational age (gestational age 2) was grouped as premature (less than 37 weeks) or not ( $\geq 37$ weeks); age at surgery (age at surgery 2) was grouped as neonate (up to 30 days of age) or not (31 days of age or older); and use of DHCA was grouped as "yes" or "no."

All predictors listed in Table 1 were tested by logistic regression for univariate prediction of PVL. Presence of PVL was coded as 1 , absence as 0 . Dichotomous variables were treated as 0,1 dummy variables. APOE genotype was grouped into 3 groups: the $\epsilon 2$ group ( $\epsilon 2 \epsilon 2$ and $\epsilon 2 \epsilon 3$ ), the $\epsilon 3 \epsilon 3$ group, and the $\epsilon 4$ group ( $\epsilon 3 \epsilon 4$ and $\epsilon 4 \epsilon 4)$. Because of the opposing effects of $\epsilon 2$ and $\epsilon 4$ in Alzheimer's disease, patients with $\epsilon 2 \epsilon 4$ were excluded. These were then considered as 2 dummy variables ( $\epsilon 2$ vs $\epsilon 3$ and $\epsilon 4$ vs $\epsilon 3)$. Any predictor of PVL that was found to have a $P$ value of .1 or less was considered in a forward stepwise logistic regression to determine a model for prediction of PVL. Gestational age and age at surgery were coded as both continuous and dichotomous in separate regressions. Use of DHCA was also considered separately from the quantitative variable length of DHCA use. The relationship of all quantitative variables in the final model for PVL prediction was plotted. The correlation structure of all predictive variables was also evaluated. All analyses used SPSS 10.0 for Windows.

\section{Results}

Between June 21, 2000, and November 5, 2001, 206 eligible infants underwent cardiac surgery. Of these $169(82 \%)$ enrolled in the study of APOE genotype and 105 of the 


\begin{tabular}{|c|c|c|c|c|c|c|c|c|}
\hline $\mathrm{DBP}_{\max }$ & $\mathrm{DBP}_{\min }$ & $H R_{\text {min }}$ & $\mathrm{Po}_{\text {2adm }}$ & $\mathrm{Po}_{2 \max }$ & $\mathrm{Po}_{2 \min }$ & $\mathrm{SBP}_{\text {adm }}$ & $\mathrm{SBP}_{\max }$ & $\mathrm{SBP}_{\text {min }}$ \\
\hline .443 & .361 & -.186 & .218 & .218 & .214 & 1.000 & .656 & .374 \\
\hline$<.001^{*}$ & $<.001^{*}$ & .058 & $.025^{*}$ & $.026^{*}$ & $.028 *$ & & $<.001^{*}$ & $<.001^{*}$ \\
\hline 105 & 105 & 105 & 105 & 105 & 105 & 105 & 105 & 105 \\
\hline .546 & .314 & -.190 & .099 & .099 & .072 & .656 & 1.000 & .603 \\
\hline$<.001^{*}$ & $.001^{*}$ & .052 & .313 & .315 & .465 & $<.001^{*}$ & & $<.001^{*}$ \\
\hline 105 & 105 & 105 & 105 & 105 & 105 & 105 & 105 & 105 \\
\hline .349 & .429 & -.165 & -.087 & -.099 & -.076 & .374 & .603 & 1.000 \\
\hline$<.001^{*}$ & $<.001^{*}$ & .093 & .378 & .315 & .442 & $<.001^{*}$ & $<.001^{*}$ & \\
\hline 105 & 105 & 105 & 105 & 105 & 105 & 105 & 105 & 105 \\
\hline
\end{tabular}

$P V L$, Periventricular leukomalacia; $D H C A$, deep hypothermic circulatory arrest; $D B P$, diastolic blood pressure; $H R$, heart rate; $S B P$, systolic blood pressure; adm, admission; max, maximum; min, minimum.

${ }^{*} P<.05$.

enrolled patients (62\%) underwent postoperative MRI. Seven of the 169 patients enrolled in the larger study (4.1\%) died prior to hospital discharge. All patients enrolled in the APOE study were approached for enrollment in the MRI study. Reasons for not undergoing MRI included discharge prior to MRI, instability precluding MRI prior to 14 days, and parental preference. Seventeen patients also participated in a simultaneous pre- and postoperative MRI study.

There were 44 girls and 61 boys. The median gestational age was 39 weeks (range 28-42) with a median birth weight of $3125 \mathrm{~g}$ (range $739-4528$ ). Twelve patients (11\%) were younger than 37 weeks gestational age. The median head circumference at birth was $34 \mathrm{~cm}$ (range 24-38, $\mathrm{n}=103$ ). Microcephaly (birth head circumference less than fifth percentile for gestational age) was present in $17 \%$ of the patients.

The median age at surgery was 6 days (range 1-178). Eighty-two patients underwent surgery as neonates. Median weight at surgery was $3.4 \mathrm{~kg}$ (range 1.5-6.9). Forty-four patients were class I, 11 were class II, 9 were class III, and 41 were class IV. HLHS was present in 33 infants, conotruncal defects in 51, and other defects in 21. DHCA was utilized in 64 patients with a median duration of 38 minutes (range 1-86). Median cooling time prior to DHCA was 15 minutes (range 8-35). Only 2 patients were cooled for less than 15 minutes. The median total support time was 88 minutes (range 13-242). The median hematocrit after hemodilution on CPB was $27 \%$ (range 20-37).

APOE genotype was completed for 98 of 105 patients (93\%). Eight were $\epsilon 2 \epsilon 2$ or $\epsilon 2 \epsilon 3$ and 26 were $\epsilon 3 \epsilon 4$ or $\epsilon 4 \epsilon 4$. The $\epsilon 3 \epsilon 3$ genotype was present in 61 patients. There were 3 patients with $\epsilon 2 \epsilon 4$.

The median postoperative day for performance of MRI was 7 (range 3-14). PVL was identified in 45 infants (43\%; Figure 1). PVL was identified in 44 of 82 neonates (54\%) compared with only 1 of 23 (4\%) older infants. The severity of PVL was mild in 36 of $45(80 \%)$, moderate in $8(18 \%)$, and severe in $1(2 \%)$. The PVL was unilateral in 16 of 45 $(36 \%)$ and bilateral in $29(64 \%)$. PVL was identified in $25 \%$ of class I patients, $36 \%$ of class II patients, $33 \%$ of class III patients, and $60 \%$ of class IV patients.

Table 1 lists all potential predictors of PVL considered and shows the regression coefficients as well as the univariate statistical significance. A positive regression coefficient suggests that the variable is positively correlated with PVL. All variables that predicted PVL at a $P \leq .1$ level were examined for their correlations. As expected, many of these variables are highly correlated (Table 2). Gestational age did not remain in the final model, regardless of whether it was quantitative or qualitative; however, the coding of age at surgery (dichotomous vs continuous) did affect the final model. In addition, no APOE genotype effect on the risk of PVL was identified. Forward logistic regression considering age at surgery as a quantitative variable identified a model containing the minimum DBP $\left(\mathrm{DBP}_{\min }\right)$ and $\mathrm{Po}_{2}\left(\mathrm{PO}_{2 \mathrm{~min}}\right)$, the SBP at CICU admission ( $\left.\mathrm{SBP}_{\mathrm{adm}}\right)$, and longer total support time as significant predictors of PVL (Table 3). It is important to note that given the highly correlated nature of the other predictors, this may not be the only useful predictive model for this set of risk factors. However, given these variables, none of the other predictors improved prediction of PVL. The direction of these effects was as expected: lower $\mathrm{DBP}_{\text {min }}$, lower $\mathrm{Po}_{2 \min }$, and lower $\mathrm{SBP}_{\text {adm }}$ all increased risk of PVL, as did longer total support time. To aid in the visualization of the relationship of these 4 variables with PVL, the subjects were grouped according to the predictor and the proportion of subjects in each group with PVL plotted (Figure 2). However, when age at surgery was dichotomized ( $\leq 30$ days or $>30$ days), it remained in the final model (Table 3), replacing $\mathrm{Po}_{2 \min }, \mathrm{SBP}_{\mathrm{adm}}$, and total 

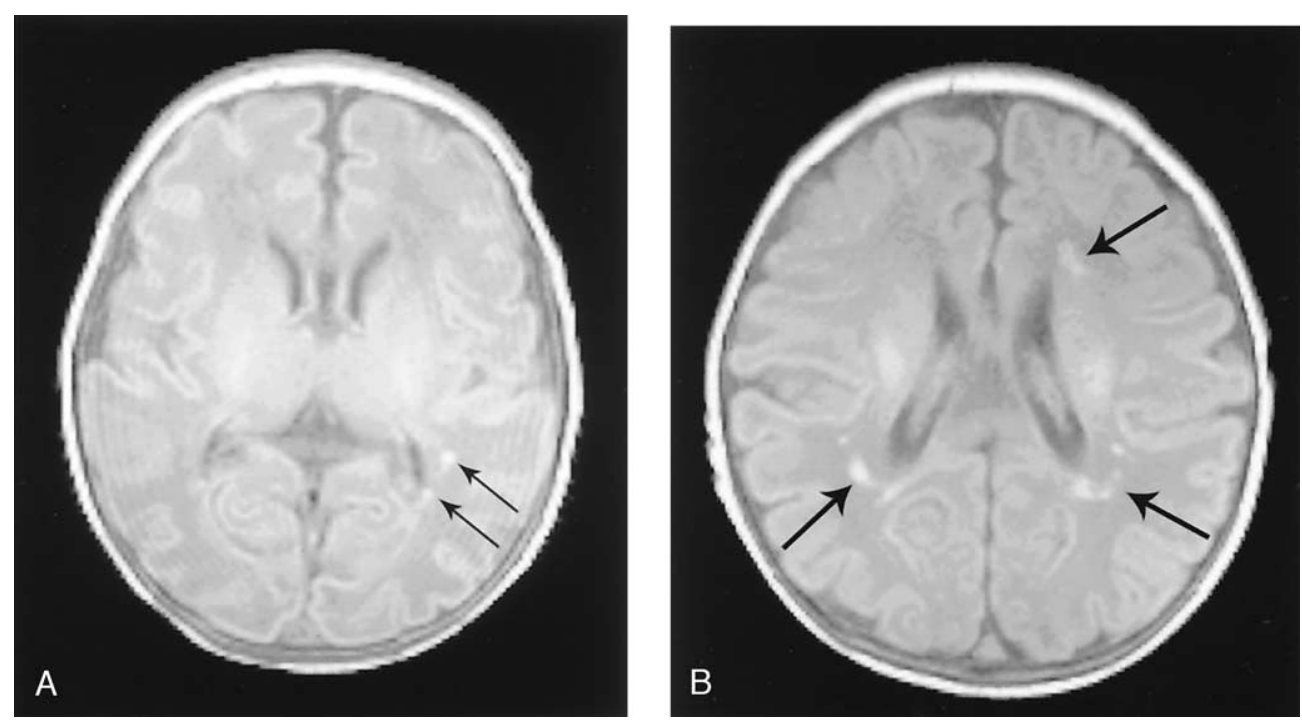

Figure 1. A, Axial MRI image (T1-weighted) demonstrating 2 small areas of increased signal intensity in the periventricular white matter consistent with PVL, classified as mild (arrows). B, Axial MRI image (T1-weighted) demonstrating multiple larger areas of increased signal density in the periventricular white matter consistent with PVL, classified as moderate (arrows).

support time as significant predictors of PVL. When the analysis was restricted to the 82 neonates, $\mathrm{DBP}_{\text {min }}$ and $\mathrm{SBP}_{\mathrm{adm}}$ remained significant predictors of PVL in the multivariable analysis with age at surgery considered as a continuous variable. $\mathrm{PO}_{2 \min }$ and longer total support time were no longer significant.

\section{Discussion}

This study demonstrates that PVL is a frequent finding on MRI of the brain following cardiac surgery in neonates. The occurrence of PVL is much less common in older infants. Prolonged exposure to CPB (with or without DHCA) is a risk factor for PVL, possibly secondary to the systemic inflammatory response to CPB. Hypotension and hypoxemia in the early postoperative period, especially diastolic hypotension, significantly increase the risk of PVL, possibly secondary to cerebral ischemia. In infants without CHD, PVL is associated with developmental dysfunction including impaired motor function, learning disabilities, and ADHD. The significance of PVL identified on an early postoperative MRI as a predictor of a long-term neurodevelopmental outcome must be determined.

PVL was described as a specific entity in 1962 by the neuropathologic studies of Banker and Larroche. ${ }^{12}$ PVL is defined by the presence of focal necrosis of all cellular elements in the deep white matter surrounding the walls of the lateral ventricles and a more diffuse injury to oligodendroglial precursors. ${ }^{13-16}$ PVL was recognized initially as a pathologic condition relatively specific to the preterm neonate; however, appreciation of its clinical significance was overshadowed by its common coexistence with more dramatic-appearing lesions such as germinal matrix, intraventricular, and parenchymal hemorrhages. Cranial ultrasonography has demonstrated that PVL may be detected in $7 \%$ to $26 \%$ of preterm infants. PVL in preterm infants is highly associated with subsequent cerebral palsy, mental retardation, learning disabilities, visual-motor deficits, and ADHD. ${ }^{13-16}$ PVL may be encountered in the term infant following significant asphyxia, hypoglycemia, meningitis, CHD, and other conditions. ${ }^{17}$ The late consequences of PVL in term infants without CHD are comparable to those in prematurity and resemble the long-term neurodevelopmental "signature" of some children following surgical repair of CHD. ${ }^{17}$

One of the key developmental processes in premature and very young infant is progression of myelination, in which precursors of myelin are created, mature, and eventually envelop axons in the cerebral hemispheres, cerebellum, brain stem, and spinal cord. There is an age-dependent window of vulnerability to injury of developing white matter. PVL is one of the hallmarks of brain injury in premature and some term infants but is much less common thereafter. The target for diffuse white matter injury in PVL is the early differentiating oligodendrocyte, histologically distinguished from its mature counterpart by the absence of myelin basic protein staining. ${ }^{16}$ Whereas mature oligodendroglia are relatively resistant to injury from conditions such as hypoxiaischemia, differentiating oligodendrocytes are exquisitely sensitive to a variety of insults, including hypoxia, ischemia, reactive oxygen species, and inflammatory media- 
tors. ${ }^{13-16,18}$ In addition to direct toxic effects, oligodendrocyte maturation may be disrupted. Clinical conditions in preterm infants that result in cerebral ischemia, such as respiratory distress syndrome, patent ductus arteriosus, hypotension, and impaired autoregulation of cerebral blood flow, are associated with the development of PVL. Previous studies have also suggested that hyperventilation producing hypocarbia is a risk factor for PVL, possibly secondary to alteration in cerebral blood flow resulting in cerebral ischemia. ${ }^{19}$ Hypocarbia was not identified as a risk factor in our study.

Cytokine networks play important roles in normal brain development. However, in some pathologic conditions, cytokines [such as tumor necrosis factor- $\alpha$ (TNF- $\alpha$ ) and interleukin-6 (IL-6)] may be directly toxic to vulnerable, immature oligodendroglia while others are indirectly toxic through glial stimulation of nitric oxide, reactive oxygen species, and excitatory amino acids. ${ }^{13-16,18}$ There is in vitro evidence that IL-6 may alter the developmental pathways of oligodendrocyte precursors away from myelinating oligodendrocytes toward astrocyte development. There is increasing evidence that the systemic inflammatory response of the fetus and neonate is an important mechanism of white matter injury. ${ }^{13-16}$ The role of the systemic inflammatory response induced by $\mathrm{CPB}$ as a mediator of white matter injury is not known.

Children with CHD are at risk for cerebral hypoperfusion and hypoxemia before, during, and after cardiac surgery. ${ }^{6}$ Use of DHCA results in a period of global cerebral ischemia. Postoperative hemodynamic instability with low cardiac output and hypotension may also decrease cerebral perfusion. Many infants are hypoxemic before and after reconstructive surgery. In addition, use of $\mathrm{CPB}$ for the repair of CHD initiates a systemic inflammatory response. ${ }^{6}$ Exposure of blood to the foreign surface of the bypass circuit results in activation of complement as well as activation of the coagulation and fibrinolytic pathways. The systemic inflammatory response includes cytokine production, neutrophil activation, and endothelial cell activation. Dramatic increases of circulating cytokines for 24 to 48 hours have been reported in many studies of patients undergoing CPB including TNF- $\alpha$ and IL-6, as well as other cytokines.

These potential risk factors do not fully explain the frequency or pattern of neurodevelopmental dysfunction. There is significant interindividual variation in developmental outcome, even among children with the same cardiac defect, suggesting that other patient-specific factors may be important determinants of CNS injury. In a recent study we demonstrated that APOE genotype, specifically the APOE $\epsilon 2$ allele, was predictive of a worse neurodevelopmental outcome at 1 year of age following neonatal and infant cardiac surgery. ${ }^{20}$ In the current study we were unable to
TABLE 3. Forward stepwise logistic regression results when age at surgery is considered as continuous (model 1 ) and dichotomous (model 2)

\begin{tabular}{lccc}
\hline Predictors & B & $\begin{array}{c}\text { Standard } \\
\text { error }\end{array}$ & $\boldsymbol{P}$ value \\
\hline Model 1 & & & \\
$\mathrm{DBP}_{\text {min }}$ & -0.141 & 0.050 & .005 \\
$\mathrm{P}_{2 \min }$ & -0.051 & 0.019 & .008 \\
$\mathrm{SBP}_{\text {adm }}$ & -0.039 & 0.020 & .045 \\
Support time $_{\text {Model 2 }}$ & 0.020 & 0.007 & .005 \\
$\quad \mathrm{DBP}_{\text {min }}$ & -0.146 & 0.470 & .002 \\
Age at surgery 2 & -2.433 & 1.076 & .024 \\
\hline
\end{tabular}

$D B P$, Diastolic blood pressure; $S B P$, systolic blood pressure; $B$, regression coefficient.

demonstrate an effect of APOE genotype as a predictor of PVL. However, given the relatively small size of the study population and the rarity of the APOE $\epsilon 2$ allele (approximately $8 \%$ of the population), the statistical power to demonstrate a genotype effect is very limited.

Prior neuropathology and autopsy studies have demonstrated that PVL is a common finding in patients with CHD. A study of 33 children with CHD who were older than 1 year of age at death demonstrated white matter injury in $75 \%$ of the brains examined postmortem. ${ }^{7}$ A neuropathologic study conducted at our institution examined expired infants with $\mathrm{HLHS}^{8}$ Both congenital and acquired abnormalities were demonstrated. The most common acquired ischemic neuropathologic lesions were PVL, present in over $25 \%$ of those examined, and localized strokes.

A recent study at our institution utilizing serial MRIs (preoperative, early postoperative, and late postoperative) in 24 patients demonstrated that PVL is common early after neonatal cardiac surgery (50\% of neonates), consistent with another study. ${ }^{21}$ Interestingly, PVL was present in $16 \%$ of the infants preoperatively, suggesting that in utero or early postnatal CNS injury had occurred. However, over $50 \%$ of the infants demonstrated new or worsened PVL on the early postoperative MRI consistent with CNS injury occurring in the intraoperative and early postoperative periods. However, PVL could no longer be demonstrated 3 to 6 months after surgery. This apparent resolution of PVL does not imply that white matter injury did not occur, but rather that more sensitive imaging techniques may be necessary after resolution of the acute injury. Few other studies have evaluated infants with brain MRI following cardiac surgery, especially in the early postoperative period. Miller and associates $^{9}$ evaluated MRI of the brain in 23 children who had undergone cardiac surgery. MRI was performed at least 2 years following cardiac surgery. Ten patients had undergone neonatal cardiac surgery. White matter injury was demonstrated in 10 of 23 patients (43\%) and in 8 of 10 $(80 \%)$ of patients who had undergone neonatal heart sur- 


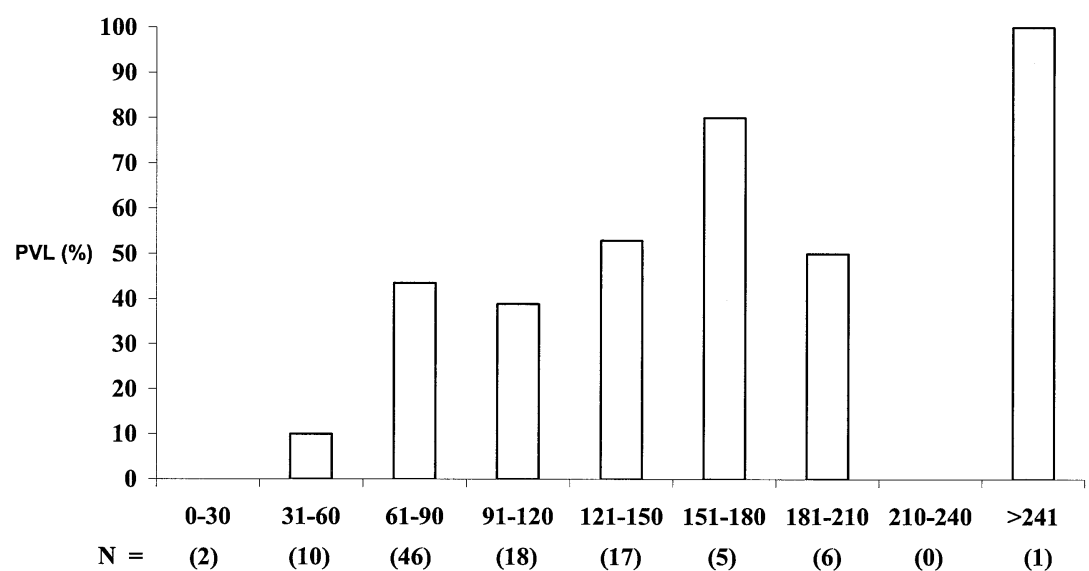

A

Total Support (CPB+DHCA) Time (min)

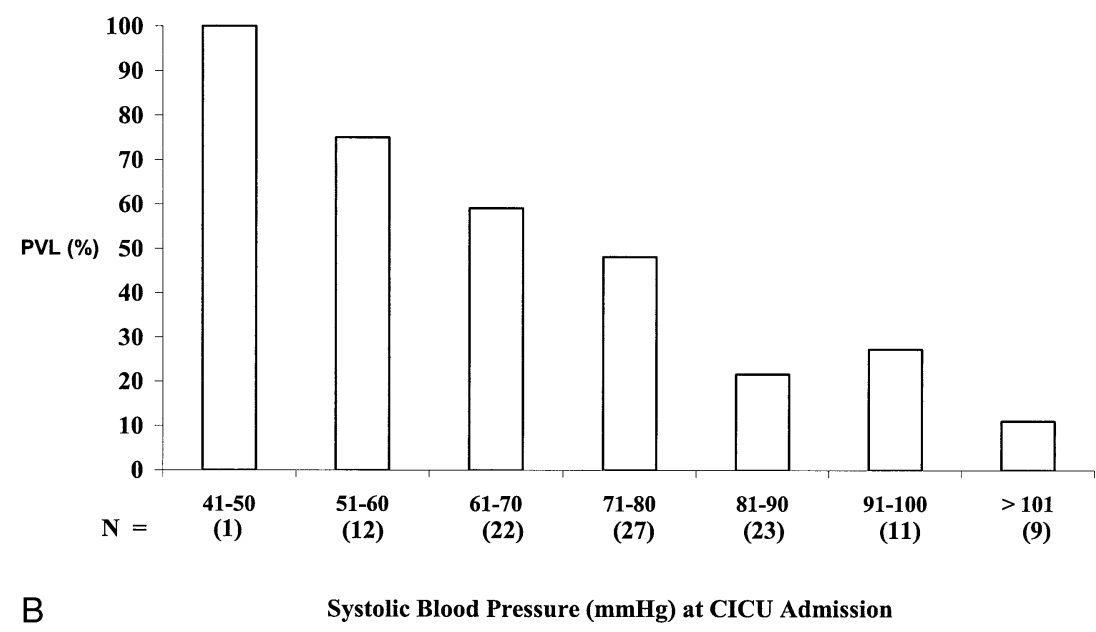

Figure 2. A, Relationship between total support time (CPB + DHCA) and the occurrence of PVL. Patients are grouped according to total support time in 30-minute intervals. The percentage of patients in each group having PVL is shown on the y-axis. B, Relationship between systolic blood pressure on admission to the CICU postoperatively and occurrence of PVL. Patients are grouped according to the systolic blood pressure initially obtained at CICU admission in increments of $10 \mathrm{~mm} \mathrm{Hg}$. The percentage of patients with PVL is shown on the y-axis.

gery. At the 1-year follow-up evaluation of the Boston Circulatory Arrest Study, MRI of the brain was performed in 142 children. ${ }^{2}$ Definite abnormalities were present in 22 patients $(15 \%)$ and possible abnormalities in $11(8 \%)$. PVL was not reported. In this study the prevalence of an MRI abnormality was related to preoperative acidosis but not to use or duration of DHCA.

There are several limitations to the current study. There is a possibility of selection bias, as not all parents of enrolled patients consented to the MRI. ${ }^{21}$ Some potential patients were discharged before the MRI could be obtained and others were deemed unstable to undergo MRI until after the study period, thus both well and ill children were excluded. Preoperative MRI was not performed; therefore, it is possible PVL was present in some patients prior to surgery. In the study by Mahle and associates ${ }^{21}$ however, PVL was present in only $16 \%$ of patients prior to surgery and new or worsened PVL was found in 52\% of patients on the early postoperative MRI. This suggests that the white matter injury most commonly occurs intraoperatively or during the early postoperative period. In addition, because PVL is an evolving lesion the time variability in the performance of the postoperative study may result in an underestimation of the incidence. Serial imaging studies may be necessary. Finally, many of the variables were highly correlated as expected (Table 2). There might be other useful risk models based on other predictors; however, none of the available predictors improved the occurrence of PVL. 


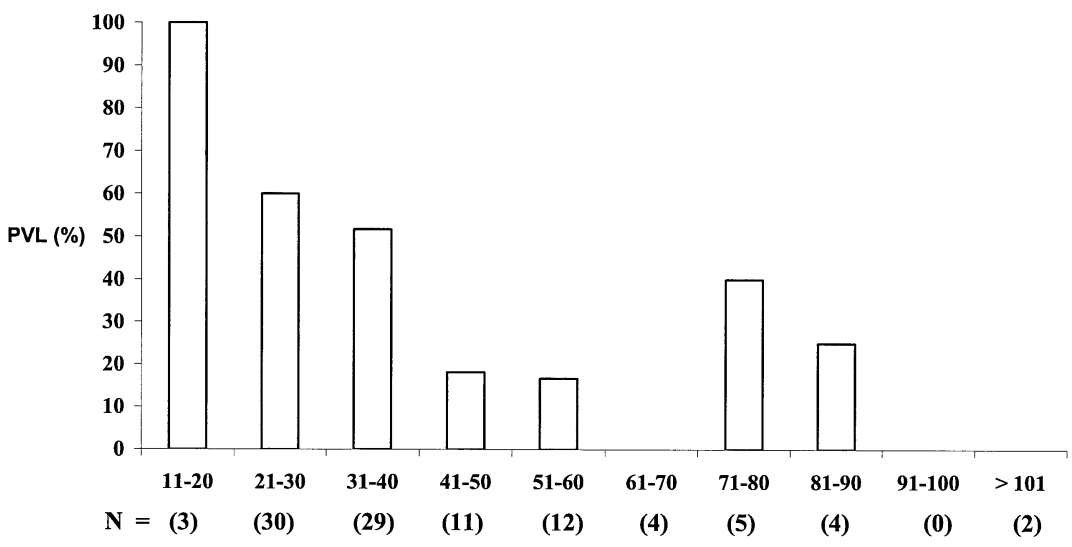

C

Minimum pO2 (mmHg)

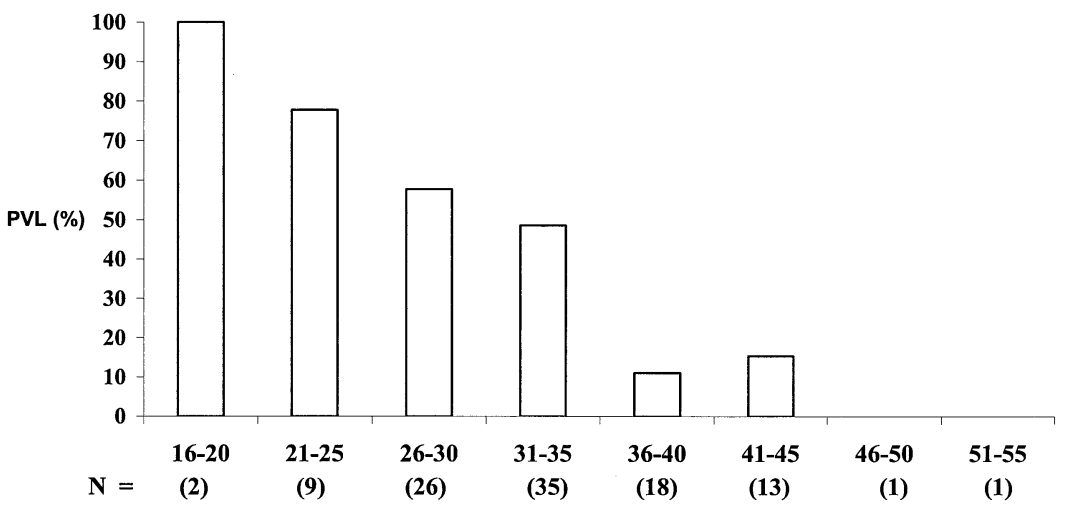

D

Minimum Diastolic Blood Pressure (mmHg)

Figure 2. Cont'd. C, Relationship between minimum $\mathrm{Po}_{2}$ during the first 48 hours postoperatively in the CICU and the occurrence of PVL. Patients are grouped according to the minimum $\mathrm{Po}_{2}$ value obtained in the first 48 hours in the CICU in increments of $10 \mathrm{~mm} \mathrm{Hg}$. The percentage of patients in each group with PVL is shown on the y-axis. D, Relationship between minimum diastolic blood pressure in the first $\mathbf{4 8}$ hours postoperatively and the occurrence of PVL. Patients were grouped according to the minimum diastolic blood pressure in increments of $5 \mathrm{~mm} \mathrm{Hg}$. The percentage of patients in each group with PVL on is shown on the y-axis.

In conclusion, this study demonstrates that cerebral white matter injury manifested as PVL is found in more than 50\% of neonates early following cardiac surgery but is rare in older infants. Prolonged exposure to CPB (with or without DHCA) and hypoxia and hypotension in the early postoperative period were associated with PVL in this population. Future studies are necessary to determine the long-term significance of PVL identified on early postoperative MRI as a marker for long-term neurodevelopmental function in these patients. Future clinical neuroprotection trials and outcome studies should include CNS imaging and detailed collection of preoperative, intraoperative, and postoperative hemodynamic variables, as these may yield important insights into the mechanisms of CNS injury in children with CHD

\section{References}

1. Newburger JW, Jonas RA, Wernovsky G, Wypij D, Hickey PR, Kuban KCK, et al. A comparison of the perioperative neurologic effects of hypothermic circulatory arrest verses low-flow cardiopulmonary bypass in infant heart surgery. $N$ Engl J Med. 1993;329: 1057-64.

2. Bellinger DC, Jonas RA, Rappaport LA, Wypij D, Wernovsky G, Kuban KCK, et al. Developmental and neurologic status of children after heart surgery with hypothermic circulatory arrest or low-flow cardiopulmonary bypass. N Engl J Med. 1995;332:549-55.

3. Bellinger DC, Wypij D, Kuban KCK, Rappaport LA, Hickey PR, Wernovsky G, et al. Developmental and neurological status of children at 4 years of age after heart surgery with hypothermic circulatory arrest or low-flow cardiopulmonary bypass. Circulation. 1999;1000:526-32.

4. Majnemer A, Limperopoulos C. Developmental progress of children with congenital heart defects requiring open-heart surgery. Semin Pediatr Neurol. 1999;6:12-9.

5. Mahle WT, Wernovsky G. Neurodevelopmental outcomes after complex infant heart surgery. ACC Curr J Rev. 2000;9:93-7. 
6. du Plessis AJ. Mechanisms of brain surgery during infant cardiac surgery. Semin Pediatr Neurol. 1999;6:32-47.

7. Gilles FB, Levitron A, Jammes J. Age-dependent changes in white matter in congenital heart disease [abstract]. J Neuropathol Exp Neurol. 1973;32:179.

8. Glauser TA, Rorke LB, Weinberg PM, Clancy RR. Acquired neuropathologic lesions associated with the hypoplastic left heart syndrome. Pediatrics. 1990;85:991-1000.

9. Miller G, Mamourian AC, Tesman JR, Baylen BG, Myers JL. Longterm MRI changes in brain after pediatric open heart surgery. $J$ Child Neurol. 1994;9:390-7.

10. Tardiff BE, Newman MF, Saunders AM, Strittmatter WJ, Blumenthal JA, White WD, et al. Preliminary report of a genetic basis for cognitive decline after cardiac operations. Ann Thorac Surg. 1997;64:715-20.

11. Clancy RR, McGaurn SA, Wernovsky G, Spray TL, Norwood WI, Jacobs ML, et al. Preoperative risk-of-death prediction model in heart surgery with deep hypothermic circulatory arrest in the neonate. $J$ Thorac Cardiovasc Surg. 2000;119:347-57.

12. Banker B, Larroche J. Periventricular leukomalacia of infancy. Arch Neurol. 1962;7:386-410.

13. Volpe JJ. Brain injury in the premature infant-from pathogenesis to prevention. Brain Dev. 1997;19:519-34.

14. Perlman JM. White matter injury in the preterm infant: an important determination of abnormal neurodevelopmental outcome. Early Hum Dev. 1998;53:99-120.

15. Rezaie P, Dean A. Periventricular leukomalacia, inflammation and white matter lesions within the developing nervous system. Neuropathology. 2002;22:106-32.

16. Volpe JJ. Neurobiology of periventricular leukomalacia in the premature infant. Pediatr Res. 2001;50:553-62.

17. Miller SP, Shevell MI, Patenaude Y, Gorman AM. Neuromotor spectrum of periventricular leukomalacia in children born at term. Pediatr Neurol. 2000;23:155-9.

18. Yonezawa M, Back S, Gan X, Rosenberg P, Volpe J. Cystine deprivation induces oligodendroglial death: rescue by free radical scavengers and a diffusible glial factor. $J$ Neurochem. 1996;67:566-73.

19. Wiswell TE, Graziani LJ, Kornhauser MS, Stanley C, Merton DA, McKee L, et al. Effects of hypocarbia on the development of cystic periventricular leukomalacia in premature infants treated with highfrequency jet ventilation. Pediatrics. 1996;98:918-24.

20. Gaynor JW, Gerdes M, Zackai E, Bernbaum J, Wernovsky G, Clancy RR, Newman M, et al. Apolipoprotein E genotype and neurodevelopmental sequelae of infant cardiac surgery. J Thorac Cardiovasc Surg. 2003;126:1736-45.

21. Mahle WT, Tavani F, Zimmerman RA, Nicolson SC, Galli KK, Gaynor JW, et al. An MRI study of neurological injury before and after congenital heart surgery. Circulation. 2002;106:109-14.

\section{Discussion}

Dr Ross M. Ungerleider (Portland, Ore). You have nicely emphasized the importance of preoperative and postoperative elements in affecting neurologic outcomes, and this is the rationale behind so many evolving management strategies for neonates before and after surgery. We need to examine outcomes over time to see if neurologic outcomes improve, despite our very aggressive approach to neonatal cardiac repair, but it is my impression that neurologic outcomes in general are improving.

I do have the following questions for you. First, if you could please tell us a little bit more about periventricular leukomalacia. Is it specific for certain kinds of injury and outcome, or is it a general MRI finding that can have many causes and correlate with variable outcomes?

Second, have you looked for PVL in neonates without cardiac disease, specifically those who are hypoxemic, such as with lung disease, or those who have diastolic hypotension, such as those who have sepsis, as opposed to just all the neonates in general who are not cardiac patients? Can you see if that break point of yours is even more notable in those patients who are hypoxemic or

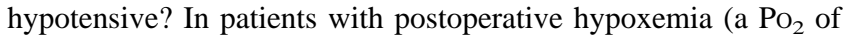
less than 40) or postoperative hypotension (a diastolic blood pressure less than 35), both of which were break points in your study, was there a correlation when this occurred in the postoperative period and the likelihood of PVL? That is, is hypoxemia or hypotension worse from the standpoint of leading to or being associated with PVL if it occurs in the first 2 days after surgery rather than if it occurs on postoperative day 4, for example?

It is interesting that you include the CPB period, since all of the patients in your study had some episode of hypotension. If you consider that there was a mean blood pressure lower than the diastolic pressure break point on CPB for most of these patients, was there any correlation between mean blood pressure on pump and PVL?

Can you tell us anything more about the follow-up correlation of PVL in your study patients and their neurologic outcomes? Obviously that's going to be very critical to knowing the importance of this study.

And finally, the implication of this study is that in our zeal to operate on neonates, we may be subjecting them to risks for neuroneural behavioral outcomes that might be different if we could wait until they were outside the neonatal period. Alternatively, it may simply be that neonates who require cardiac repair have an inherent risk for adverse neurologic outcome. It would be interesting if you could reexamine your data in a manner that could help us understand that. For example, is there a difference between babies with a single diagnosis such as TOF with respect to their association with PVL related to the timing of operation?

Dr Gaynor. Thank you very much, Dr Ungerleider. I will try to go through your questions.

PVL represents cerebral white matter injury, that is, axonal injury, oligodendrocyte injury. PVL specifically affects the white matter tracts and that has been confirmed in pathologic studies. There is some unpublished data from our institution comparing MRI findings with the pathologic findings in a small group of infants who died. Our radiologists and neuropathologists have demonstrated that these MRI findings are specific for PVL. So it is not really a general MRI finding. It is specific for white matter injury and correlates with injury to the white matter tracts. There is often subsequent delayed myelination. The findings seen on early MRI may be related to the edema and other changes associated with early cell injury; therefore, later MRIs may not show white matter injury. You see loss of volume, with increased ventricles and decreased brain volume, suggesting white matter loss, but the acute effects of edema have all resolved.

We haven't looked for PVL in neonates without cardiac disease, but the patient population in which PVL was described is in the neonatal intensive care unit, in the preterm infants, and it has been associated with a variety of factors, with hypoxemia, with respiratory distress syndrome in these infants, and with hypotension. So these are risk factors in the neonatal patient without cardiac disease, but most of those studies have been done in preterm infants.

Regarding the break points, we didn't specifically look for break points. We were just looking at the graphs. It does look like there are break points, particularly for the $\mathrm{PO}_{2}$ and the diastolic blood pressure. 
We don't know whether intervention to improve oxygenation or raise the blood pressure would prevent PVL. That's obviously the next study. I don't think you can make that leap from this study, that if we can avoid hypoxemia of less than 40 and a diastolic blood pressure of less than 35 we will prevent PVL, but I think that could be an important hypothesis for future studies.

And I do think that the timing of the occurrence of hypoxemia and hypotension probably is very important. The early postoperative period after an episode of bypass or a period of deep hypothermic circulatory arrest, or even if the children had been sick preoperatively, is a vulnerable period that even if you had not irreversibly injured neurons or the oligodendrocytes, an additional insult in that early postoperative period results in neuronal death. So I think if you are further past surgery, you may be less vulnerable to injury. Again, that will need to be tested.

We did not look at the mean pressures on bypass. That would be an interesting future study.

These infants have come back for neurodevelopmental evaluation at 1 year of age, assessed with a neurologic exam and the Bailey's scales of infant development, but we haven't analyzed the data yet. That hopefully will be a future presentation.

As far as the implications regarding the elective neonatal surgery, when we looked at the distribution in the first month of life, it was pretty much even, whether it was week $1,2,3$, or 4 , and the real break point occurred at about 30 days. Now, I don't know if it is colinear with cardiac diagnosis (the reason the children are having the surgery) or whether it is related to the physiology and the maturation of the oligodendrocytes.

I think it would be interesting to study in the future whether or not it's better to operate on patients with TOF when they are 1 week old if they are asymptomatic or if it's better to wait until they are 2 months old, taking risk of increasing cyanosis. But I think we should consider that operating on neonates who may be vulnerable simply because we feel it is better to do this in the neonatal period may not always for every child be the best option.

Dr James S. Tweddell (Milwaukee, Wis). My question really involves the finding of decreased diastolic pressure as a risk factor. Obviously pressure is dependent on the systemic vascular resistance and total cardiac output, or cardiac output. I was wondering if you could give us any insight into which of those 2 factors seem to have the most impact on the development of PVL, or if you are able to sort that out at all? Really, it relates to whether a patient with good cardiac output and a low diastolic pressure is at greater risk as a patient whose diastolic hypotension is due primarily to low output.

Dr Gaynor. Well, we weren't able to evaluate that in the study, but I think that's a very interesting question. What controls cerebral blood flow in the early postoperative period, and how is the blood flow distributed through the body? Is it systemic vascular resistance? Is it cerebrovascular resistance? I know you are going to present some data later on looking at that. I'm sure total cardiac output is important. One of the really important messages of this article is that the early postoperative period is a time of risk for these children. We have focused so much on what we do in the operating room and the use versus nonuse of DHCA that we sometimes do not consider the intensive care unit. We have to concentrate on protecting the brain in the early postoperative period. We need to do studies where we actually assess the adequacy of cerebral blood flow, either looking at cerebral oxygenation or some measure of cerebral blood flow, and then determine whether an intervention that will increase blood pressure by increasing systemic vascular resistance will improve cerebral blood flow. Alternatively we can try to increase cardiac output and hope that the flow distribution will improve cerebral blood flow.

I think that's something we really need to begin to look at. We are not able to answer that from that study, but I think this is something that is clearly important as we go forward.

Dr Glen Van Arsdell (Toronto, Ontario, Canada). That was a beautiful presentation and study and has some important implications for us, and you've alluded to some. I wanted to just see whether I could get you to further delineate how you analyzed this.

Obviously, one of the simmering debates is the timing of repair in certain lesions, and the Boston neurologic outcome data have suggested that if you have prolonged intubation, it may well affect your long-term neurologic outcome. Have you tried to correlate the 2 factors, time of intubation and age at repair, to see whether or not that had any impact on PVL? And second, have you looked at a continuous variable to preoperative oxygen saturation and whether or not that had any impact on PVL?

Dr Gaynor. We haven't looked at those factors specifically. We did do a study with Dean Kurth, who is now at Cincinnati, using near-infrared spectroscopy to look at cerebral oxygenation preoperatively. In some subgroups, particularly patients with hypoplastic left heart syndrome, it can be dangerously low in the preoperative period. That was not measured in this study, and this does not occur in every infant. Some of these children were infants who came in for elective surgery.

But I think it is important to focus on the preoperative period, the potential for injury in the preoperative period. How we are setting these patients up for surgery? Can we optimize their condition, their cerebral blood flow, in the preoperative period, so perhaps they are less vulnerable for the operative period?

In our previous study, the incidence of PVL prior to surgery or at the time of surgery is fairly low, 16\%, compared with approximately $50 \%$ postoperatively. So I think most of the injury is occurring either intraoperatively or in the early postoperative period. But we may be setting kids up. If we take a patient who has dangerously low cerebral oxygenation to the operating room, he may be more vulnerable than another child.

We did not look at duration of ventilation. I don't know that the problem is the duration of ventilation per se, it may be, or is it just a surrogate for some other marker of illness, or if there is some other problem going on. I don't know. We didn't look at that in these data. We could go back and look at that, but we haven't thus far.

Dr Frank L. Hanley (Stanford, Calif). The most dramatic finding you showed, Bill, was the difference in the insult between neonates and nonneonates. On initial assessment of these findings, it seems clear that that there is either something very different in the way neonates and relatively young infants respond or there is something different in your management techniques between neonates and nonneonates. One or both of these may be very important here. The similarities and differences in the management schemes of these 2 groups were not presented. Can you review whether you use different bypass techniques, hematocrits, or other factors when treating neonates as compared with older infants that 
could give us some insights into the overall management differences during and shortly after bypass between the 2 groups?

Dr Gaynor. The management strategies and the bypass strategies are fairly similar. The older children probably have a lower incidence of deep hypothermic circulatory arrest, but obviously the neonate state is colinked to many other variables, particularly diagnosis. The patients with HLHS were all neonates. That means the neonates had a greater incidence of the use of circulatory arrest. So there may be some colinking there, and these other factors are important. But there are also physiologic differences in the neonatal brain. The oligodendrocytes are not fully mature at birth. There is a maturation period that occurs after birth; it may be that the oligodendrocytes in the neonate are more vulnerable to injury than those of the older infants. I think there are a lot of things that are related, and we need to sort out what those factors are.
Dr Hanley. Can you give us just a very brief overview of when you did not use DHCA? What was the standard so-called "continuous bypass management," in terms of did you go low flow, how low, for how long a period of time, things like that?

Dr Gaynor. That again, we would have to go back and look at it specifically because it is highly variable between the surgeons doing the cases. Some of these children were 6 months old who underwent ventricular septal defect closure and had continuous bypass at full flow with mild to moderate hypothermia; others were neonates who had fairly deep hypothermia and low flow bypass for a period of time. We haven't broken that out in terms of the specific bypass strategies. That is something we could look at, but it is not a uniform technique for this study and wasn't controlled as a factor for this study.

\section{Authoritative}

The Journal of Thoracic and Cardiovascular Surgery is the most frequently cited thoracic/cardiovascular surgery journal in the Science Citation Index. An article in JTCVS is cited on average almost twice as

often as those in the closest cardiothoracic journal. 